\title{
Effect of moist heat reprocessing of N95 respirators on SARS-CoV-2 inactivation and respirator function
}

Simeon C. Daeschler MD, Niclas Manson MPH, Kariym Joachim MSc, Alex W.H. Chin PhD, Katelyn Chan MHSc, Paul Z. Chen BASc, Kiana Tajdaran MD, Kaveh Mirmoeini MD, Jennifer J. Zhang MD PhD, Jason T. Maynes MD PhD, Libo Zhang MD, Michelle Science MD, Ali Darbandi PhD, Derek Stephens MSc, Frank Gu PhD, Leo L.M. Poon PhD, Gregory H. Borschel MD

Cite as: CMAJ 2020 October 13;192:E1189-97. doi: 10.1503/cmaj.201203; early-released July 30, 2020

\begin{abstract}
BACKGROUND: Unprecedented demand for $\mathrm{N} 95$ respirators during the coronavirus disease 2019 (COVID-19) pandemic has led to a global shortage of these masks. We validated a rapidly applicable, lowcost decontamination protocol in compliance with regulatory standards to enable the safe reuse of $\mathrm{N} 95$ respirators.
\end{abstract}

METHODS: We inoculated 4 common models of N95 respirators with severe acute respiratory syndrome coronavirus 2 (SARS-CoV-2) and evaluated viral inactivation after disinfection for 60 minutes at $70^{\circ} \mathrm{C}$ and $0 \%$ relative humidity. Similarly, we evaluated thermal disinfection at $0 \%$ to $70 \%$ relative humidity for masks inoculated with Escherichia coli. We assessed masks subjected to multiple cycles of thermal disinfection for structural integrity using scanning electron microscopy and for protective functions using standards of the United States National Institute for Occupational Safety and Health for particle filtration efficiency, breathing resistance and respirator fit.

RESULTS: A single heat treatment rendered SARS-CoV-2 undetectable in all mask samples. Compared with untreated inoculated control masks, E. coli cultures at 24 hours were virtually undetectable from masks treated at $70^{\circ} \mathrm{C}$ and $50 \%$ relative humidity (optical density at $600 \mathrm{~nm}$ wavelength, $0.02 \pm 0.02 \mathrm{v}$. $2.77 \pm 0.09, p<0.001$ ), but contamination persisted for masks treated at lower relative humidity. After 10 disinfection cycles, masks maintained fibre diameters similar to untreated masks and continued to meet standards for fit, filtration efficiency and breathing resistance.

INTERPRETATION: Thermal disinfection successfully decontaminated N95 respirators without impairing structural integrity or function. This process could be used in hospitals and long-term care facilities with commonly available equipment to mitigate the depletion of N95 masks.
A s the coronavirus disease 2019 (COVID-19) pandemic has overwhelmed many health care systems worldwide, the unprecedented demand for personal protective equipment (PPE) has exhausted stockpiles and interrupted global supply chains for $\mathrm{N} 95$ respirators. Currently, the proportion of frontline health care workers among individuals infected with severe acute respiratory syndrome coronavirus 2 (SARS-CoV-2) exceeds $10 \%$ in some regions and is expected to increase if PPE stockpiles diminish further. ${ }^{1,2}$ As a result, protecting front-line workers from SARS-CoV-2 infection is now an immediate global concern. ${ }^{3}$

Disposable $\mathrm{N} 95$ respirators protect users against infectious airborne particles and are therefore critical to front-line workers during the COVID-19 pandemic. ${ }^{3}$ However, the present global shortage of PPE has forced regulating institutions to adjust infection control measures. Before the pandemic, guidelines recommended disposal of $\mathrm{N} 95$ respirators after each patient encounter. Now, evolving guidelines instruct staff to reuse 1 mask over their whole shift, or even longer. ${ }^{4}$ This policy of reusing disposable masks in the setting of high airborne pathogen exposure - such as aerosol-generating medical procedures in the care of patients with COVID-19 - may result in accumulation of contagious material on the mask surface, risking the health and safety of personnel and patients. ${ }^{5,6}$ Inactivating accumulated pathogens in disposable respirators without affecting the respirators' protective properties may enable safe reuse and thus help to alleviate the current global shortage temporarily. However, the sterilization methods regularly used in health care institutions potentially degrade disposable respirators and thereby affect fit or filtration efficiency. ${ }^{7}$ 
Thermal disinfection may overcome this issue and provide a widely available and cost-effective decontamination strategy for disposable respirators. Recent reports show a high sensitivity to heat for SARS-CoV-2, as 5 minutes of heating at $70^{\circ} \mathrm{C}$ inactivates the virus. ${ }^{5,8}$ The polypropylene microfibres in commercially available $\mathrm{N} 95$ respirators have a thermal degradation point above $130^{\circ} \mathrm{C}$, suggesting that the filter may withstand repetitive exposure to $70^{\circ} \mathrm{C} \cdot{ }^{9,10}$ However, the viricidal efficacy of thermal disinfection for $\mathrm{N} 95$ respirators contaminated with SARS-CoV-2, and the protective performance of heat-treated respirators, have not been validated to a level meeting regulatory standards in the United States.

We therefore investigated whether thermal disinfection at $70^{\circ} \mathrm{C}$ for 60 minutes inactivates pathogens, including SARS-CoV-2, while maintaining critical protective properties of N95 respirators for multiple cycles of disinfection and reuse in a real-world setting.

\section{Methods}

\section{Thermal disinfection protocol for $\mathrm{N} 95$ respirators}

We used thermal disinfection in cycles of 60 minutes at $70^{\circ} \mathrm{C}$, at either $0 \%$ or $50 \%$ relative humidity, to treat 4 common models of commercially available N95 respirators (8110s, 9105s, 8210 and 1860s; 3M). We wrapped the respirators in sterilization pouches (Steril-Peel, GS Medical Packaging) before disinfection. To control for temperature and relative humidity, we set the BevLes Heated Holding Cabinet with humidity (BevLes Inc.) to $70^{\circ} \mathrm{C}$ and varied the humidity between $0 \%$ and $50 \%$ relative humidity. We used a digital thermo- and hygrometer (Hagen Group Inc., Canada) as an added quality-control measure. Additionally, we accounted for potential real-world temperature fluctuations by cooling the masks to room temperature for 5 minutes mid-cycle.

\section{Inactivation of SARS-CoV-2}

We assessed inactivation of SARS-CoV-2 in all 4 N95 respirator models. We cut unprocessed and 10x heat-treated N95 respirators into $1 \mathrm{~cm}^{2}$ pieces and inoculated the outer surface of the respirators with $5 \mu \mathrm{L}$ of SARS-CoV-2 (about 7.8 log $50 \%$ tissue culture infective dose per $\left.\mathrm{mL}\left[\mathrm{TCID}_{50} / \mathrm{mL}\right]\right)$ in triplicates $(n=3$ per respirator type) in a biosafety level 3 laboratory. The virusinoculated respirators underwent thermal disinfection at $70^{\circ} \mathrm{C}$ at $0 \%$ relative humidity for 60 minutes, with and without a 5-minute cool-down mid cycle, followed by soaking in $300 \mu \mathrm{L}$ of viral transport medium for 30 minutes for virus elution. We then titrated the recovered infectious virus particles by standard $\mathrm{TCID}_{50}$ assay, using Vero E6 cells as described. ${ }^{5}$ We used virus-inoculated respirator surfaces without the heat inactivation step as controls.

\section{Bacterial inactivation}

To test for bacterial inactivation, we cut unprocessed N95 respirators (1860S; 3M) into $1 \mathrm{~cm}^{2}$ pieces. We inoculated the outer surface with $100 \mu \mathrm{L}$ of Escherichia coli $\left(4 \times 10^{8}\right.$ colony-forming units [CFU] per $\mathrm{mL}$, optical density 0.612 at $600 \mathrm{~nm}$ ) and inoculated a negative control with pure Luria-Bertani medium. The inoculated respirators underwent 60 minutes of heat treatment at $70^{\circ} \mathrm{C}$ at either $0 \%$, $25 \%$ relative humidity, $40 \%$ relative humidity, or $50 \%$ relative humidity ( $n=4$ per condition). We treated a high-temperature control sample at $90^{\circ} \mathrm{C} / 70 \%$ relative humidity and left a positive, E. coli-inoculated control at room temperature for 1 hour. We then washed N95 fragments individually in $1 \mathrm{~mL}$ of Luria-Bertani medium and inoculated $100 \mu \mathrm{L}$ washing media on Luria-Bertani agar plates. We counted colonies after 24 hours of incubation at $37^{\circ} \mathrm{C}$ (Figure 1). To the $900 \mu \mathrm{L}$ of remaining washing media and N95 fragments, we added $9.1 \mathrm{~mL}$ Luria-Bertani media and incubated it at $37^{\circ} \mathrm{C}$ in a shaking incubator. We read optical density at $600 \mathrm{~nm}$ (Epoch Microplate Spectrophotometer, BioTek) after 24 hours of incubation to estimate bacteria concentration.

\section{Microstructural analysis of the N95 filter layer}

To assess whether exposing the polymer microfibres of the N95 filter media to high temperatures caused fibre degradation, we analyzed a $1 \mathrm{~cm}^{2}$ filter sample from unprocessed respirators and respirators that underwent 10 thermal disinfection cycles at $70^{\circ} \mathrm{C}$ and $0 \%$ relative humidity, or $50 \%$ relative humidity. We coated each sample with $10 \mathrm{~nm}$ of carbon and imaged them with a scanning electron microscope (XL30, FEI) at magnifications of $\times 150, \times 200$, $\times 650$ and $\times 1200$ at $5 \mathrm{keV}$. We analyzed fibre morphology with a blinded observer using ImageJ (https://imagej.nih.gov/ij/) in 10 randomly selected individual fibres from all quadrants of a representative image of each sample. We measured the fibre diameters in 40 individual fibres per condition (10 fibres per mask type) to calculate the mean fibre diameter after each disinfection cycle.

\section{Quantitative N95 respirator fit testing}

Exposure to high temperatures may affect the mechanical properties of the respirator components, such as elasticity of the headbands or adjustability of the nose clip, potentially allowing for leakage of particles. To test the respirator fit, we applied a standardized, quantitative fit testing procedure in a total of 46 respirators ( $n=12$ per type, except $n=10$ for 1860 s) using a PortaCount Pro+ Respirator Fit Tester 8038 (TSI Incorporated) and a particle generator model 8026 (TSI Incorporated) in compliance with governmental regulatory guidelines (the United Kingdom Health and Safety Executive, US Occupational Safety and Health Administration [OSHA] and Canadian Standards Association $[\mathrm{CSA}]) .{ }^{11-13}$ Particles greater than $0.02 \mu \mathrm{m}$ in size were detected in a concentration range of 0.01 to $2.5 \times 10^{5}$ particles $/ \mathrm{cm}^{3}$. We measured average ambient and in-mask particle concentration during standardized exercises and calculated their ratio as the respirator fit factor, with a fit factor of 100 being defined by the OSHA as the minimum pass value. ${ }^{11}$ Fitted respirators were personalized to 2 blinded test participants ( 1 male, 1 female) and underwent thermal disinfection at $0 \%$ or $50 \%$ relative humidity, respectively ( $n=23$ each), as outlined above. After 5, 10 and 15 disinfection cycles, we repeated the quantitative fit testing for each respirator, with the same test participant. Additionally, the blinded test participant rated the subjective fit, adjustability and comfort of each decontaminated respirator compared with the unprocessed reference masks, according to the CSA Comfort Assessment Score ( 0 - no issues; 1 - discomfort can be ignored; 2 - some discomfort but still able to function; 4 - unacceptable discomfort). ${ }^{13}$ 

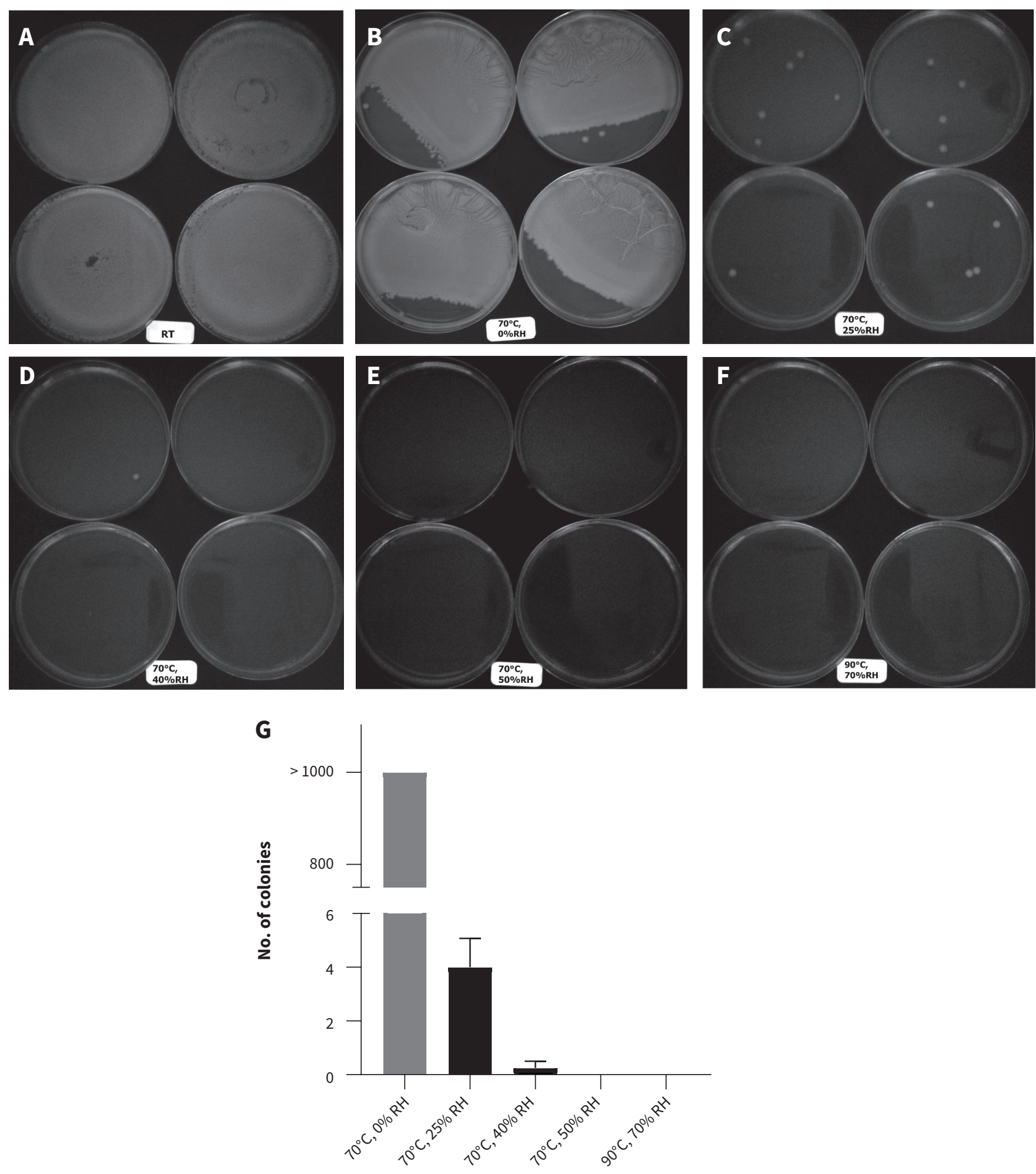

Thermal disinfection protocol

Figure 1: Bacterial inactivation in thermally disinfected N95 respirators. (A-F) Escherichia coli colonies after $24 \mathrm{~h}$ incubation at $37^{\circ} \mathrm{C}$ derived from inoculated N95 respirators that underwent thermal disinfection at different temperatures and humidity. We used 4 samples of 1 model (1860s; $3 \mathrm{M}$ ) for each condition, inoculated with $\mathrm{E}$. coli $(n=20)$. Of those, 4 were left at room temperature (positive control, panel A) and 20 underwent thermal disinfection under different conditions: (B) $70^{\circ} \mathrm{C} / 0 \%$ relative humidity (RH); (C) $70^{\circ} \mathrm{C} / 25 \% \mathrm{RH}$; (D) $70^{\circ} \mathrm{C} / 40 \% \mathrm{RH}$; (E) $70^{\circ} \mathrm{C} / 50 \% \mathrm{RH}$; (F) $90^{\circ} \mathrm{C} / 70 \% \mathrm{RH}$ as a high-temperature control; $n=4$ per condition. (G) The E. coli colony count derived from the same samples after $24 \mathrm{~h}$ incubation at $37^{\circ} \mathrm{C}$. These results show that 60 minutes of heat treatment at $70^{\circ} \mathrm{C}$ and $50 \% \mathrm{RH}$ thoroughly inactivates $E$. coli in contaminated N95 respirators. 


\section{N95 filter efficiency and breathing resistance testing} We determined the breathing resistance and particulate filter efficiency in $n=12$ unprocessed masks and in a total of $n=58$ N95 respirators that underwent either 5 or 10 cycles of thermal disinfection at $0 \%$ or $50 \%$ relative humidity, using the abbreviated National Institute for Occupational Safety and Health (NIOSH) standard. ${ }^{14-16}$ To measure breathing resistance, we mounted the respirators on a test fixture with air flowing at a rate of $85 \pm 2 \mathrm{~L} / \mathrm{min}$. In accordance with the NIOSH standard, a breathing resistance below $343.23 \mathrm{~Pa}$ is considered tolerable. ${ }^{16}$ For NIOSH filtration efficiency protocols, we preconditioned the respirators at $85 \pm 5 \%$ relative humidity and $38 \pm 2.5^{\circ} \mathrm{C}$ for $25 \pm 1$ hour and then mounted them on a certified condensation particle counter (model 3772, TSI Incorporated). We tested the respirators against a near monodispersed polystyrene latex bead at a flow rate of $85 \pm 2 \mathrm{~L} / \mathrm{min}$, at $21-26^{\circ} \mathrm{C}$ and $30.4 \%$ $43.2 \%$ relative humidity. We calculated particle filter efficiency as the percentage of all counted particles (median diameter $0.075 \pm$ $0.020 \mu \mathrm{m}$ ) removed by the respirator. For N95 masks, particle filter efficiency must be equal to or greater than $95 \% .{ }^{15}$

\section{Statistical analysis}

We conducted statistical analyses using JMP (version 15.1.0; SAS Institute). We calculated descriptive statistics among all tested respirators for each condition. All means are expressed with standard deviation ( \pm SD). Given the limited sample size owing to the global shortage of N95 respirators, we used 1-sample $t$ tests to compare the group means of the disinfected masks to the respective US-regulatory pass value for each assessment. Sample size calculations for quantitative respirator fit showed a required sample size of $n=12$ to detect a mean fit factor of 120 (pass value 100, mean fit factor of unprocessed mask $190 \pm 15$ ) on an $\alpha$ level of 0.01 and a power of $0.95 .{ }^{17}$ We chose an $\alpha$ level of 0.01 for 1 -sided $p$ values to increase the stringency and adjust for multiple comparisons. Additionally, we assumed US-regulatory compliance of the disinfected masks only when the lower bound of the $99 \%$ confidence intervals (CIs) was greater than the minimum required pass value. See Table 1 for further details on the experimental design and statistical methods used.

\section{Table 1: Experimental design*}

\section{Evaluation}

SARS-Cov-2 inactivation

Bacterial inactivation

Microstructural analysis of the N95 filter layer

Quantitative N95 respirator fit testing

Filtration efficiency and breathing resistance testing

\section{Experimental design and sample size}

3 samples $\times 4$ models $=12$ virus-inoculated pieces per condition ( $60 \mathrm{~min}$ heated, $60 \mathrm{~min}$ heated with $5 \mathrm{~min}$ cool-down mid cycle, nonheated control)

4 samples $\times 1$ model $(1860 \mathrm{~s} ; 3 \mathrm{M})=$ (room temp.; $70^{\circ} \mathrm{C}$ at $0,25,40,50 \% \mathrm{RH}$; and $90^{\circ} \mathrm{C}$ at $70 \% \mathrm{RH}$ ) plus 4 samples $\times 1$ model $(1860 \mathrm{~s} ; 3 \mathrm{M})=4$ noninoculated control pieces at room temp (neg control)

10 fibres in 1 sample $\times 4$ models $=40$ fibres for 3 conditions (unprocessed, 10x disinfected at $0 \% \mathrm{RH}$ or $50 \% \mathrm{RH}$ )

\section{Outcome}

\section{Statistical methods}

SARS-Cov-2 $\left(\mathrm{TCID}_{50} / \mathrm{mL}\right) \quad$ - Mean $\pm \mathrm{SD}$ for each model and condition 4 bacteria-inoculated pieces per condition

Escherichia coli (OD600 and number of colonies)

Fibre diameter

Fit factor CSA Comfort Assessment Score $(1860 \mathrm{~s} ; 3 \mathrm{M})=46$ respirators in total; of those, $n=23$ masks respectively underwent repetitive disinfection $(5 \times, 10 x$ and $15 x)$ at $0 \%$ or $50 \%$; for each condition, 2 test participants tested 12 and 11 respirators, respectively
3 masks $\times 4$ models $=12$ unprocessed masks; plus 3 masks $\times 4$ models $=12$ masks for each condition at 50\% RH ( $5 \times$ and $10 \times$ disinfected) plus 4 masks $\times 2$ models + 5 masks $\times 2$ models $(8210,9105$ second; $3 \mathrm{M})=$ 18 masks were $5 \times$ disinfected at $0 \%$ RH plus 4 masks $\times 4$ models $=16$ masks were $10 \times$ disinfected at $0 \% \mathrm{RH}$
Filtration efficiency (percentage of particles removed by the respirator) breathing resistance

\author{
- Mean \pm SD for each condition \\ - 2-tailed, independent $t$ tests to compare \\ group means with positive control
}

- Mean \pm SD of pooled fibre diameter for each condition (models have similar $3 \mathrm{M}$ electret filter)

- Compare group mean to the upper and lower boundary of the fibre diameter range for unprocessed N95 filters as specified in the US patent using 1-tailed, 1-sample $t$ tests

- Mean fit factor \pm SD for each condition

- Compare group mean for each condition against standard - fit factor of 100 (OSHA-defined standard pass value for sufficient respiratory protection), using 1-tailed, 1-sample $t$ tests

- Report subjective fit and wearing comfort of the decontaminated respirators compared with new reference masks on the CSA Comfort Assessment Score

- Mean filtration and breathing resistance \pm SD for each condition

- Compare group mean for each condition against 95\% filtration efficiency standard (NIOSH-defined standard pass value for N95 respirators) using 1-tailed, 1 -sample $t$ tests

- Compare group mean for each condition against breathing resistance standard of $343.23 \mathrm{~Pa}$ (NIOSH-defined standard pass value for $\mathrm{N} 95$ respirators) using 1 -tailed, 1 -sample $t$ tests

Note: $\mathrm{CSA}=$ Canadian Standards Association, $\mathrm{NIOSH}=$ National Institute for Occupational Safety and Health, OD600 = optical density at $600 \mathrm{~nm}, \mathrm{OSHA}=\mathrm{Occupational} \mathrm{Safety} \mathrm{and} \mathrm{Health}$ Administration, $\mathrm{RH}=$ relative humidity, SARS-Cov-2 = severe acute respiratory syndrome coronavirus $2, \mathrm{SD}=$ standard deviation, $\mathrm{TCI} \mathrm{D}_{50} / \mathrm{mL}=50 \%$ tissue culture infective dose per $\mathrm{mL}$.

*Shown is the experimental design of the study including sample size per respirator model, the outcome metrics and the statistical methods used. 


\section{Results}

\section{Inactivation of SARS-CoV-2}

After dry heat treatment $\left(70^{\circ} \mathrm{C}\right.$ for $\left.60 \mathrm{~min}\right)$, no infectious SARS-CoV-2 could be detected in any of the previously virus-inoculated respirators, whereas high levels of SARS-CoV-2 could still be detected in respirators that had not undergone heat treatment (Table 2).

\section{Bacterial inactivation}

No E. coli could be detected in inoculated N95-respirators when heat treated for 60 minutes at $70^{\circ} \mathrm{C}$ at $50 \%$ relative humidity or at $90^{\circ} \mathrm{C}$ at $70 \%$ relative humidity. As shown in Figure 1 , in samples exposed to dry heat $\left(70^{\circ} \mathrm{C} / 0 \%\right.$ relative humidity), more than
1000 bacterial colonies were still detectable, while exposure to $70^{\circ} \mathrm{C}$ with humidity ( $25 \%$ and $40 \%$ relative humidity) dramatically reduced colony formation. Consequently, thermal disinfection for 60 minutes at $70^{\circ} \mathrm{C}$ and $50 \%$ relative humidity eliminated E. coli contamination on $\mathrm{N} 95$ respirators (Table 3, Figure 1).

\section{Structural properties of the N95 filter}

We analyzed the N95 filter media in new, unprocessed (control) respirators and observed an overall mean fibre diameter of $3.88 \pm$ $2 \mu \mathrm{m}$. Even after 10 cycles of thermal disinfection of 60 minutes at $70^{\circ} \mathrm{C}$ at either $0 \%$ or $50 \%$ relative humidity, the mean overall fibre diameter remained within the range for unprocessed N95 filters as specified in the US patent (Figure 2). ${ }^{9}$

\begin{tabular}{|c|c|c|c|c|}
\hline \multirow[b]{2}{*}{$\begin{array}{l}\text { N95 model } \\
\text { (3M) }\end{array}$} & \multirow[b]{2}{*}{ Pretreatment } & \multicolumn{3}{|c|}{ Titre, $\log \mathrm{TCID}_{50} / \mathrm{mL}($ mean $\pm \mathrm{SD})$} \\
\hline & & $\begin{array}{c}\text { Control } \\
\text { (no heat treatment) }\end{array}$ & $\begin{array}{c}70^{\circ} \mathrm{C} / 0 \% \mathrm{RH}, \\
60 \mathrm{~min}\end{array}$ & $\begin{array}{l}70^{\circ} \mathrm{C} / 0 \% \mathrm{RH}, 60 \mathrm{~min} \\
\text { with } 5 \text {-min } \\
\text { cool-down mid cycle }\end{array}$ \\
\hline \multirow[t]{2}{*}{$1860 \mathrm{~S}$} & Unprocessed & $5.62 \pm 0.21$ & $U$ & $U$ \\
\hline & $10 \times$ heat treated & $5.69 \pm 0.11$ & $U$ & $\mathrm{U}$ \\
\hline \multirow[t]{2}{*}{$8110 \mathrm{~S}$} & Unprocessed & $5.70 \pm 0.004$ & $U$ & $U$ \\
\hline & $10 \times$ heat treated & $5.77 \pm 0.24$ & $\mathrm{U}$ & $U$ \\
\hline \multirow[t]{2}{*}{$8210 \mathrm{~S}$} & Unprocessed & $5.21 \pm 0.50$ & $\mathrm{U}$ & $\mathrm{U}$ \\
\hline & $10 \times$ heat treated & $5.66 \pm 0.08$ & $\mathrm{U}$ & $U$ \\
\hline \multirow[t]{2}{*}{$9105 S$} & Unprocessed & $5.56 \pm 0.27$ & $\mathrm{U}$ & $\mathrm{U}$ \\
\hline & $10 \times$ heat treated & $5.45 \pm 0.29$ & $U$ & $U$ \\
\hline \multicolumn{5}{|c|}{ 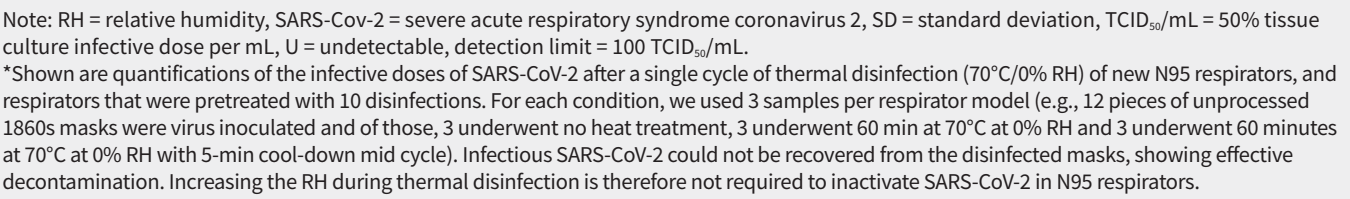 } \\
\hline
\end{tabular}

Table 3: Bacterial quantification in N95 respirators after thermal disinfection using optical density measurement at $600 \mathrm{~nm}$ wavelength after $24-\mathrm{h}$ culture*

\begin{tabular}{|c|c|c|c|c|c|c|c|}
\hline $\begin{array}{l}\text { Sample } \\
\text { no. }\end{array}$ & $\begin{array}{c}\text { Negative } \\
\text { control }\end{array}$ & $\begin{array}{c}\text { Room } \\
\text { temperature }\end{array}$ & $\begin{array}{c}70^{\circ} \mathrm{C}, \\
0 \% \mathrm{RH}\end{array}$ & $\begin{array}{c}70^{\circ} \mathrm{C}, \\
25 \% \mathrm{RH}\end{array}$ & $\begin{array}{c}70^{\circ} \mathrm{C}, \\
40 \% \mathrm{RH}\end{array}$ & $\begin{array}{c}70^{\circ} \mathrm{C}, \\
50 \% \mathrm{RH}\end{array}$ & $\begin{array}{c}90^{\circ} \mathrm{C} \\
70 \% \mathrm{RH}\end{array}$ \\
\hline 1 & 0 & 2.777 & 2.875 & 2.74 & 2.84 & 0 & 0 \\
\hline 2 & 0.001 & 2.851 & 2.861 & 2.625 & 2.768 & 0.04 & 0 \\
\hline 3 & 0.002 & 2.816 & 2.912 & 2.709 & 2.733 & 0.02 & 0 \\
\hline 4 & 0 & 2.64 & 2.736 & 2.748 & 0 & 0 & 0 \\
\hline Mean \pm SD & $0.00 \pm 0.00$ & $2.77 \pm 0.09$ & $2.84 \pm 0.08$ & $2.71 \pm 0.06$ & $2.09 \pm 1.39$ & $0.02 \pm 0.02$ & $0.00 \pm 0.00$ \\
\hline$p$ valuet & $<0.001$ & - & 0.842 & 0.863 & 0.081 & $<0.001$ & $<0.001$ \\
\hline \multicolumn{8}{|c|}{$\begin{array}{l}\text { Note: } E \text {. coli }=\text { Escherichia coli, } \mathrm{OD} 600=\text { optical density measurement at } 600 \mathrm{~nm} \text { wavelength, } \mathrm{RH}=\text { relative humidity, } \mathrm{SD}=\text { standard deviation. } \\
\text { *Shown are quantifications of } E \text {. coli as OD } 600 \text { readings. We used } 4 \text { samples of } 1 \text { model }(1860 \mathrm{~s} ; 3 \mathrm{M}) \text { for each condition. The negative control was } \\
\text { inoculated with pure Luria-Bertani medium and left at room temperature. Of the } E \text {. coli-inoculated N95 respirator pieces }(n=24), 4 \text { were left at } \\
\text { room temperature (positive control) and } 20 \text { underwent thermal disinfection under different conditions }\left(70^{\circ} \mathrm{C} \text { at } 0,25,40,50 \% \mathrm{RH} \text { and } 90^{\circ} \mathrm{C} \text { at } 70 \%\right. \\
\mathrm{RH}, n=4 \text { per condition). These results show that thermal disinfection eliminates } E \text {. coli when relative humidity is kept to } 50 \% \text {, but not below. } \\
\dagger \text { Compared with the positive control (E. coli-inoculated samples left at room temperature). }\end{array}$} \\
\hline
\end{tabular}



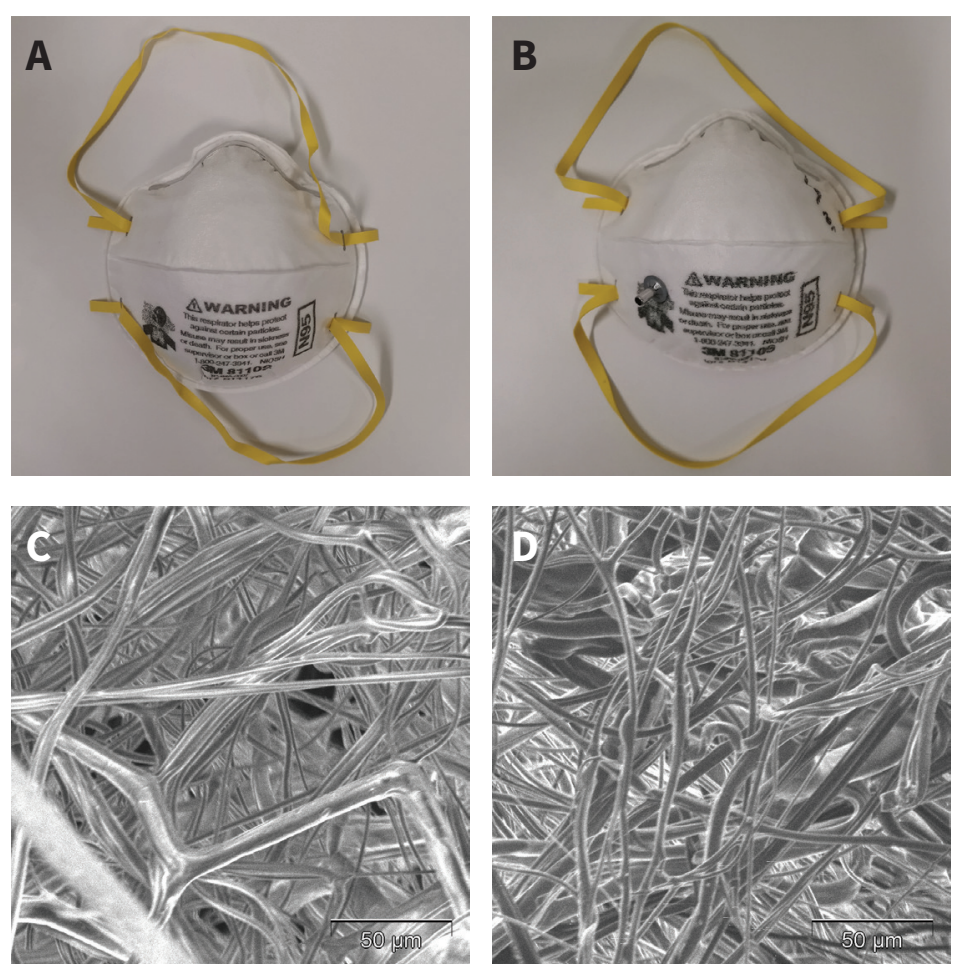

$\mathbf{E}$

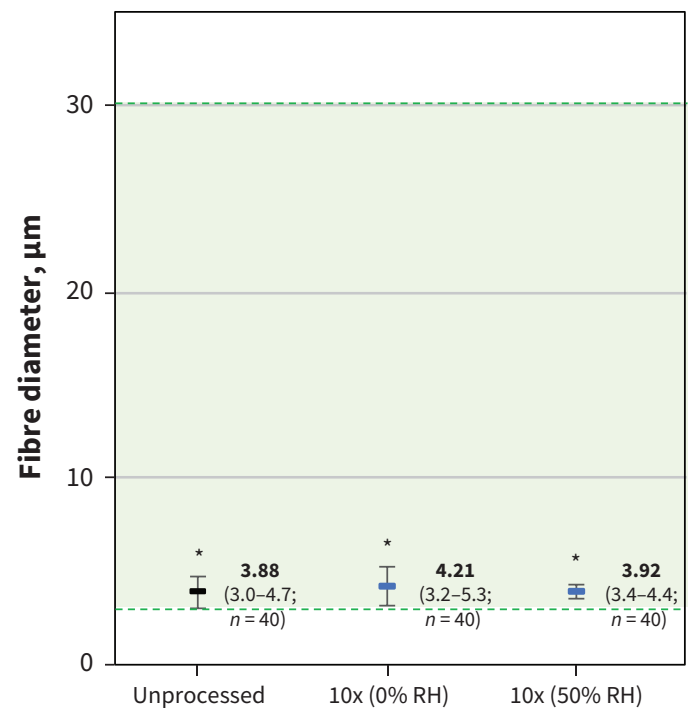

No. of completed disinfections

Figure 2: The effect of thermal disinfection on the structural properties of N95 respirators. (A and C) An unprocessed N95 respirator; (B and D) a N95 respirator after 10 thermal disinfections at $50 \%$ relative humidity $(\mathrm{RH})$ (both model $8110 \mathrm{~s} ; 3 \mathrm{M}$ ). (C and D) The N95 filter layer in $\times 650$ magnification (scanning electron microscopy image, scale bar $50 \mu \mathrm{m})$. (E) The fibre diameter of unprocessed and 10x disinfected N95 filters ( $0 \%$ and $50 \% \mathrm{RH})$, with the fibre diameter range of new (unprocessed) 3M N95 filters shaded in green. ${ }^{9}$ Compared with the boundaries of this range, the group means of the tested unprocessed and $10 \times$ disinfected masks remain significantly lower than the upper boundary $(p<0.001$ for all groups) and significantly exceed the lower boundary of the fibre diameter range of 3M N95 filters, as stated in the US patent (unprocessed: $p=0.004 ; 10 \times$ disinfected at $0 \%$ RH: $p=0.002$ and $10 \times$ disinfected at 50\% RH: $p<0.001$ ). Groups that significantly differ from both boundaries are labelled with an asterisk ( $\left.{ }^{*} p<0.01\right)$. For all 4 tested N95 models, we used 1 sample per model and measured 10 randomly chosen fibres per sample (i.e., 40 fibres per condition). Shown are the mean fibre diameters with $99 \%$ confidence intervals (Cls) as error bars. Graphs are labelled with mean and $99 \% \mathrm{Cl}$ and number of measured fibres in brackets.

\section{Respirator function}

We conducted quantitative fit testing with 4 common types of commercially available $\mathrm{N} 95$ respirators that underwent 5,10 and then 15 cycles of thermal disinfection at $0 \%$ and $50 \%$ relative humidity, respectively ( $n=23$ for each condition; Figure 3 ). All tested groups of thermally disinfected respirators significantly exceeded the fit factor of 100 , the OSHA-defined standard pass value for sufficient respiratory protection $(p<0.001$ for all groups), and so did the lower bound of their $99 \% \mathrm{Cls}$ (Figure 3). In a total of 138 performed quantitative fit tests with disinfected respirators ( $0 \%$ and $50 \%$ relative humidity), none failed the test. In addition, the subjective fit and wearing comfort of the decontaminated respirators did not differ from new masks and were rated 0 , or no issues, on the CSA Comfort Assessment Score.

Further, we tested the particle filtration efficiency and breathing resistance in the same 4 types of commercially available N95 respirators that underwent 5 cycles or 10 cycles of thermal disinfection at $0 \%$ and $50 \%$ relative humidity, respectively (Figure 3). The disinfected respirators significantly exceeded $95 \%$ filtration efficiency after 5 and 10 disinfection cycles $(p<0.001)$. In addition, the breathing resistance of the same set of disinfected respirators was significantly lower than the maximum tolerable resistance standard of $343.23 \mathrm{~Pa}$ for all tested groups $(p<0.001)$.

\section{Interpretation}

Following recent reports that showed the heat sensitivity of SARSCoV-2, we applied thermal disinfection to 4 common, disposable N95 respirator models. ${ }^{5,8}$ We found that a single thermal disinfection cycle of 60 minutes at $70^{\circ} \mathrm{C}$ and $0 \%$ relative humidity effectively inactivated SARS-CoV-2 in 4 types of N95 respirators and similarly eliminated $E$. coli when relative humidity was kept at 50\% or higher. Moreover, we found that thermal disinfection did not compromise the physical structure of respirators' electret filter media; nor did it compromise fit, filtration performance, breathing resistance or wearing comfort of the respirators for at least 10 cycles of thermal disinfection at $0 \%$ and $50 \%$ relative humidity.

Given the high demand for PPE during the COVID-19 pandemic, front-line workers are often instructed to reuse disposable N95 respirators. ${ }^{4,18}$ Strategies to disinfect and redistribute personalized N95 respirators would increase the safety of health care workers and mitigate depletion of the supply. However, until now, a safe and universally available large-scale decontamination protocol for $\mathrm{N} 95$ respirators was not available.

To effectively cope with the global supply shortage, strategies for disinfection and reuse require widespread scale-up. The US Food and Drug Administration recently issued emergency use 


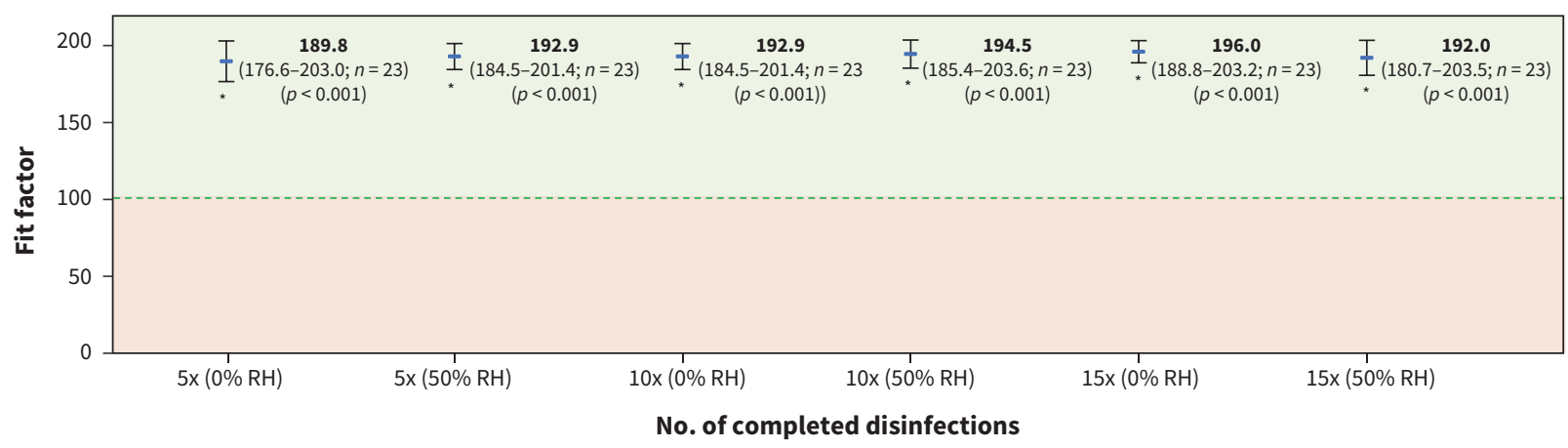

B Filtration efficiency

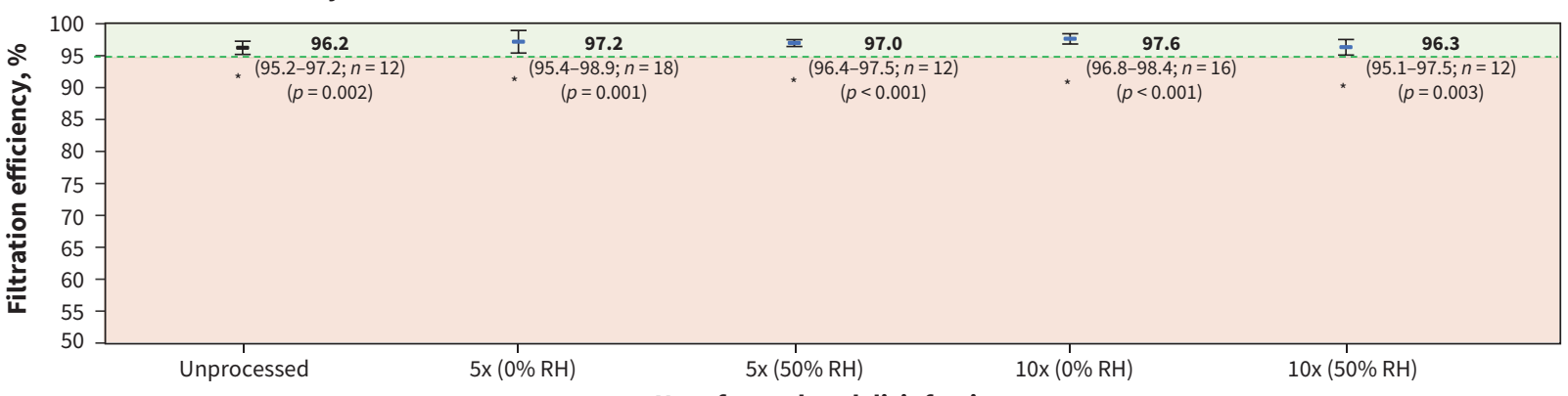

No. of completed disinfections

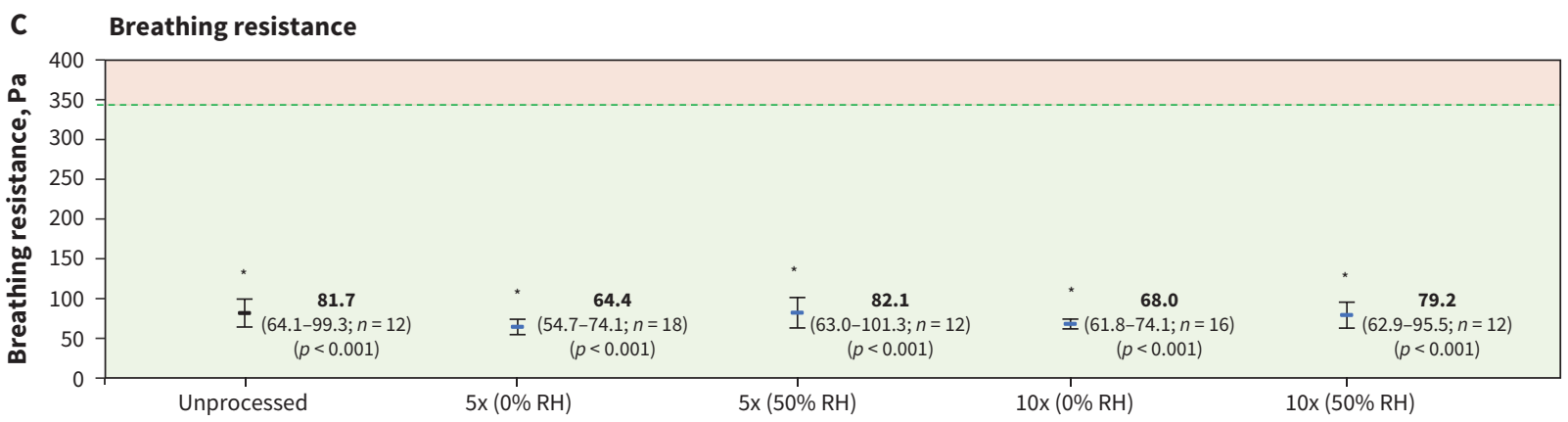

No. of completed disinfections

Figure 3: Function of thermally disinfected N95 respirators. (A) Quantitative fit factors of thermally disinfected N95 respirators after 5,10 and 15 cycles at $0 \%$ or $50 \%$ relative humidity (RH), respectively ( $n=23$ masks per condition, with 6 masks of each of 3 models and 5 masks of the 1860 s model). The fit factor of 100 as the pass value defined by the Occupational Safety and Health Administration is shown by a dashed line. ${ }^{11}$ (B) Particle filtration efficiency (percentage of particles removed by the respirator). (C) Breathing resistance (airflow resistance) of unprocessed N95 respirators ( $n=$ 12 masks per condition, with 3 masks per model for 4 models) and of thermally disinfected N95 respirators after 5 and $10 \mathrm{cycles}$ at $0 \%$ or $50 \%$ RH, respectively ( $5 \times$ disinfected at $0 \% \mathrm{RH}: 18$ masks, with 4 masks per model for 2 models [8110s, 1860s; 3M] and 5 masks per model for 2 models [ 8210 , 9105; 3M]; 10× disinfected at 0\% RH: 16 masks, with 4 masks per model for 4 models; $5 \times$ and 10× disinfected at 50\% RH, respectively: $n=12$ masks, with 3 masks per model for 4 models). The pass values defined by the National Institute for Occupational Safety and Health ( $\geq 95 \%$ filtration efficiency and $\leq 343.23$ Pa breathing resistance) are shown by a dashed line. ${ }^{15,16}$ Data are displayed as means with $99 \%$ confidence intervals (Cls) and labelled with the mean and the $99 \% \mathrm{Cl}$ and sample size in brackets. Groups that significantly exceeded the respective pass value are labelled with an asterisk ( ${ }^{*} p<0.01$ ). $P$ values are shown for the comparison of each group mean with the official US pass value for each metric.

authorizations for the vapourized hydrogen peroxide gas sterilization of disposable $\mathrm{N} 95$ respirators. ${ }^{21,22}$ Vapourized hydrogen peroxide exposure inactivates SARS-CoV-2 and other pathogens in N95 respirators and maintains their quantitative fit for at least 3 decontamination cycles. ${ }^{23,24}$ However, this technology is limited to noncellulose-based respirators, therefore making a large proportion of
N95s ineligible for reprocessing, and is also unavailable in most hospitals and other facilities. ${ }^{25}$ Thermal disinfection can be performed at low cost in conventional mechanical convection ovens, which are widely available in commercial kitchens, laboratories or sterilization facilities. Their large capacity enables the simultaneous disinfection of thousands of masks per oven per day, 
allowing for the process to potentially be scaled to a level sufficient to expand the supply of PPE globally. Thermal disinfection may thereby provide a feasible solution for selected low- and middleincome regions with limited access to PPE and limited testing capacities, helping to protect their front-line personnel during the COVID-19 pandemic.

In agreement with our findings, a recent report shows inactivation of SARS-CoV-2 in N95 respirators after 60 minutes' exposure to $70^{\circ} \mathrm{C}$ dry heat. ${ }^{23}$ Others have shown that shorter thermal disinfection protocols ( 15 to $40 \mathrm{~min}$ at $75^{\circ} \mathrm{C}$ to $100^{\circ} \mathrm{C}$ and $0 \%$ to $100 \%$ relative humidity) maintain the fit and filtration of N95 respirators after multiple disinfection cycles, but without testing the viricidal effects of those protocols. ${ }^{26-29}$

Beyond thermal disinfection, alternative decontamination procedures have been studied, including ultraviolet (UV) light irradiation (250-280 nm), autoclaving or chemical treatments using $70 \%$ ethanol or $2 \%$ chlorine solutions (some references from non-peer-reviewed preprint)..$^{23,28-35}$ Autoclaving and chemical treatments have been shown to rapidly degrade filtration efficiency of N95 respirators and are therefore ineligible for clinical use. ${ }^{23,28,34-36}$ In contrast, UV light decontamination systems may represent a promising approach as they seem to maintain respirator function and inactivate SARS-CoV-2. ${ }^{23,33}$ However, the scalability of UV decontamination may be limited, as stacking of the masks and consequent shadowing may further impair the limited penetration depth of UV light in porous N95 filter material. ${ }^{28}$

In conjunction with alternative reprocessing strategies, thermal disinfection can be used as a rapidly applicable emergency measure to alleviate the present global shortage of N95 respirators. Future studies may compare safety, scalability and costeffectiveness of those decontamination strategies for N95 respirators and specifically investigate SARS-CoV-2 inactivation in respirators contaminated with body fluids such as saliva or blood, to further determine safety in real-world conditions.

\section{Limitations}

Owing to the global shortage of N95 respirators, the available sample size was limited in this study. A traditional noninferiority design comparing disinfected to unprocessed masks would require large sample sizes (i.e., 155 masks per group for a fit factor noninferiority limit of 5 at a power of 0.9 and an $\alpha$ of 0.05 ) or unreasonable wide noninferiority margins. We therefore compared disinfected masks to the OSHA and NIOSH criteria for N95 respirator approval to determine their safety. Further, with respect to caring for patients with COVID-19, N95 respirators may be contaminated with virus-containing body fluids such as blood, potentially necessitating a longer heat exposure for virus inactivation. To account for that, we increased the exposure time to 60 minutes and suggest that visibly contaminated masks not be reprocessed. Another potential limitation of the study is that we did not individually test all components of the respirator (e.g., elastic straps) for complete virus inactivation. However, virus within the tested electret filter media is likely to be relatively resistant to heat disinfection compared with other respirator components, suggesting a low risk for elastic straps or other components to remain infective after thermal disinfection.

\section{Conclusion}

Thermal disinfection for 60 minutes at $70^{\circ} \mathrm{C}$ inactivates SARS-CoV-2; this method uses widely available equipment to enable the safe reuse of disposable N95 respirators without affecting their protective performance. Given the thorough SARS-CoV-2 inactivation and superior bacterial inactivation, we suggest thermal disinfection at $50 \%$ relative humidity for up to 10 times. This may provide a feasible, effective and rapidly scalable method for low-tech regions and thereby help to protect front-line workers from job-related risk of infection during the COVID-19 pandemic globally.

\section{References}

1. Coronavirus disease 2019 (COVID-19) situation report - 82. Geneva: World Health Organization; 2020. Available: www.who.int/docs/default-source/coronaviruse/ situation-reports/20200411-sitrep-82-covid-19.pdf?sfvrsn=74a5d15_2 (accessed 2020 Apr. 11).

2. COVID-19 Taskforce of the Department of Infectious Diseases and the IT Service. Integrated surveillance of COVID-19 in Italy. Rome (Italy): L'epidemiologia per la sanità pubblica, Istituto Superiore di Sanità; 2020. Available: www.epicentro.iss.it/ en/coronavirus/bollettino/Infografica_10aprile\%20ENG.pdf (accessed 2020 Apr. 11).

3. Rational use of personal protective equipment for coronavirus disease (COVID 19) and considerations during severe shortages: interim guidance. Geneva: World Health Organization; 2020. Available: www.who.int/publications/i/item/rational -use-of-personal-protective-equipment-for-coronavirus-disease-(covid-19)-and -considerations-during-severe-shortages (accessed 2020 Apr. 11).

4. Recommended guidance for extended use and limited reuse of N95 filtering facepiece respirators in healthcare settings. Cincinnati: National Institute for Occupational Safety and Health (NIOSH), Centers for Disease Control and Prevention; 2020. Available: www.cdc.gov/niosh/topics/hcwcontrols/ recommendedguidanceextuse.html (accessed 2020 Apr. 11).

5. Chin AWH, Chu JTS, Perera MRA, et al. Stability of SARS-CoV-2 in different environmental conditions. Lancet Microbe 2020;1:e10. doi: 10.1016/S2666-5247(20)30003-3.

6. Casanova L, Rutala WA, Weber DJ, et al. Coronavirus survival on healthcare personal protective equipment. Infect Control Hosp Epidemiol 2010;31:560-1.

7. Decontamination of $3 \mathrm{M}$ filtering facepiece respirators, such as N95 respirators, in the United States: considerations - Revision 8 [technical bulletin]. St. Paul (MN): 3M Company; 2020. Available: https://multimedia.3m.com/mws/ media/18248690/decontamination-methods-for-3m-n95-respirators-technical -bulletin.pdf (accessed 2020 May 6).

8. Domingo MC. Inactivation thermique du virus SARS-CoV-2 dans echantillons cliniques. Quebec Indlsp. IDBM: Institut national de la santé publique Quebec; 2020. Available: www.inspq.qc.ca/sites/default/files/lspq/rapport-inactivation _thermique_sars-cov-2.pdf (accessed 2020 April 11).

9. Angadjivand SJ, M.; Meyer, D.E., inventor; 3M Co, assignee. Electret filter media. US2000 [patent]. Available: https://patents.justia.com/patent/6119691 (accessed 2020 April 11)

10. Windholz M, editor. The Merck index: an encyclopedia of chemicals and drugs. 9th ed. Rahway (NJ): Merck \& Co. Inc.; 1976.

11. Appendix A to $\$ 1910.134$ - Fit testing procedures (mandatory). Part 1. OSHAaccepted fit test protocols. A. Fit testing procedures - general requirements. Washington (DC): Occupational Safety and Health Administration; 2020. Available: www.osha.gov/laws-regs/regulations/standardnumber/1910/1910.134A ppA (accessed 2020 Apr. 11).

12. Guidance on respiratory protective equipment (RPE) fit testing. Leaflet INDG479. Health and Safety Executive; 2019. Available: www.hse.gov.uk/ pubns/indg479.pdf (accessed 2020 Apr. 11).

13. CAN/CSA-Z94.4-18: selection, use, and care of respirators. CSA Group; 2018:1-163. Available: https://store.csagroup.org/ccrz__ProductDetails?viewState=DetailView \&cartID=\&sku=CAN/CSA-Z94.4-18\&isCSRFlow=true\&portalUser=\&store=\&cclcl=en _US (accessed 2020 Apr. 11).

14. National Institute for Occupational Safety and Health, National Personal Protective Technology Laboratory. Determination of particulate filter efficiency level for N95 series filters against solid particulates for non-powered, air-purifying respirators standard testing procedure (STP). Procedure No TEB-APR-STP-0059. Revision: 32. Pittsburgh (PA): National Personal Protective Technology Laboratory (NPPTL), Centers for Disease Control and Prevention; 2019. Available: www.cdc.gov/niosh/ npptl/stps/pdfs/TEB-APR-STP-0059-508.pdf (accessed 2020 Apr. 11). 
15. 42 CFR 84.181: Non-powered air-purifying particulate filter efficiency level determination. Washington (DC): U.S. Government Publishing Office; 2009.

16. 42 CFR 84.180: Airflow resistance tests. Washington (DC): U.S. Government Publishing Office; 2009.

17. Faul F, Erdfelder E, Lang A-G, et al. G*Power 3: a flexible statistical power analysis program for the social, behavioral, and biomedical sciences. Behav Res Methods 2007;39:175-91.

18. Summary for healthcare facilities: strategies for optimizing the supply of N95 respirators during the COVID-19 response. Atlanta: Centers for Disease Control and Prevention; updated 2020 Apr. 16. Available: www.cdc.gov/coronavirus /2019-ncov/hcp/checklist-n95-strategy.html (accessed 2020 Apr. 10).

19. Huang S-H, Chen C-W, Kuo Y-M, et al. Factors affecting filter penetration and quality factor of particulate respirators. Aerosol Air Qual Res 2013;13:162-71. doi: 10.4209/aaqr.2012.07.0179.

20. Lin $\mathrm{T}-\mathrm{H}$, Chen $\mathrm{C}-\mathrm{C}$, Huang $\mathrm{S}-\mathrm{H}$, et al. Filter quality of electret masks in filtering 14.6-594 nm aerosol particles: effects of five decontamination methods. PLOS One 2017;12:e0186217.

21. Hinton, DM. Authorization EU. (EUA) for the emergency use of the Advanced Sterilization Products, Inc. (ASP) STERRAD 100S, NX, and 100NX Sterilization Systems. Rockville (MD): US Food and Drug Administration; 2020 June 6. Available: www.fda.gov/media/136884/download (accessed 2020 Apr. 15).

22. Emergency Use Authorization (EUA) for the emergency use of Stryker Instrument's Sterizone VP4 Sterilizer. Rockville (MD): US Food and Drug Administration; 2020 June 6. Available: www.fda.gov/media/136976/download (accessed 2020 Apr. 16).

23. Fischer RJ, Morris DH, van Doremalen N, et al. Effectiveness of N95 respirator decontamination and reuse against SARS-CoV-2 virus. Emerg Infect Dis 2020 June 3;26 [Epub ahead of print]. doi: 10.3201/eid2609.201524.

24. Ibáñez-Cervantes G, Bravata-Alcántara JC, Nájera-Cortés AS, et al. Disinfection of N95 masks artificially contaminated with SARS-CoV-2 and ESKAPE bacteria using hydrogen peroxide plasma: impact on the reutilization of disposable devices. Am J Infect Control 2020 July 6 [Epub ahead of print]. S0196-6553(20)30639-8. doi: 10.1016/j.ajic.2020.06.216.

25. Fact sheet for healthcare personnel on emergency use of STERRAD ${ }^{\circledR}$ sterilization systems to reprocess N95 respirators. Irvine (CA): Advanced Sterilization Products; 2020. Available: www.asp.com/sites/default/files/covid-19/2000014-Fact_ Sheet_for_Healthcare_Personnel_on_Emergency_Use_of_STERRAD_Sterilization_ Systems_to_Reprocess_N95_Respirators.pdf (accessed 2020 May 6).
26. Anderegg L, Meisenhelder C, Ngooi CO, et al. A scalable method of applying heat and humidity for decontamination of N95 respirators during the COVID-19 crisis. PLoS One 2020;15:e0234851.

27. Li DF, Cadnum JL, Redmond SN, et al. Steam treatment for rapid decontamination of N95 respirators and medical face masks. Am J Infect Control 2020;48: 855-7.

28. Liao L, Xiao W, Zhao M, et al. Can N95 respirators be reused after disinfection? How many times? ACS Nano 2020;14:6348-56.

29. Zulauf KE, Green AB, Nguyen Ba AN, et al. Microwave-generated steam decontamination of $\mathrm{N} 95$ respirators utilizing universally accessible materials. medRxiv 2020 Apr. 25. doi: 10.1101/2020.04.22.20076117.

30. Liao L, Xiao W, Zhao M, et al. Can N95 respirators be reused after disinfection? And for how many times? ACS Nano 2020;14:6348-56.

31. Kumar A, Kasloff SB, Leung A, et al. N95 mask decontamination using standard hospital sterilization technologies. medRiv 2020 Apr. 20 [preprint]. doi: 10.1101 /2020.04.05.20049346

32. Smith JS, Hanseler $\mathrm{H}$, Welle J, et al. Effect of various decontamination procedures on disposable N95 mask integrity and SARS-CoV-2 infectivity. medRiv 2020 May 7 [preprint]. doi: 10.1101/2020.04.11.20062331.

33. Decontamination of $3 \mathrm{M}$ filtering facepiece respirators, such as N95 respirators, in the United States: considerations [technical bulletin]. Revision 9. St. Paul (MN): 3M Company; 2020. Available: https://multimedia.3m.com/mws/media/ $18248690 /$ decontamination-methods-for-3m-filtering-facepiece-respirators -technical-bulletin.pdf (accessed 2020 June 11).

34. Grinshpun SA, Yermakov M, Khodoun M. Autoclave sterilization and ethanol treatment of re-used surgical masks and N95 respirators during COVID-19: impact on their performance and integrity. J Hosp Infect 2020;105:608-14.

35. Lin $\mathrm{T}-\mathrm{H}$, Chen $\mathrm{C}-\mathrm{C}$, Huang $\mathrm{S}-\mathrm{H}$, et al. Filter quality of electret masks in filtering 14.6-594 nm aerosol particles: effects of five decontamination methods. PLoS One 2017;12:e0186217.

36. Grossman J, Pierce A, Mody J, et al. Institution of a novel process for N95 respirator disinfection with vaporized hydrogen peroxide in the setting of the COVID-19 pandemic at a large academic medical center. J Am Coll Surg 2020 Apr. 27 [Epub ahead of print] S1072-7515(20)30349-5. doi: 10.1016/j.jamcollsurg .2020.04.029.
Competing interests: No competing interests were declared.

This article has been peer reviewed.

Affiliations: SickKids Research Institute (Daeschler, Chan, Tajdaran, Mirmoeini, Darbandi), The Hospital for Sick Children (SickKids); The Hospital for Sick Children (SickKids) Occupational Health and Safety (Manson); Division of Plastic and Reconstructive Surgery (Joachim, J. Zhang), The Hospital for Sick Children (SickKids) and University of Toronto, Toronto, Ont.; School of Public Health, LKS Faculty of Medicine (Chin, Poon), The University of Hong Kong, Pokfulam, Hong Kong Special Administrative Region, China; Chemical Engineering \& Applied Chemistry (Chen, Gu), University of Toronto; Department of Anesthesia and Pain Medicine (Maynes, L. Zhang) and Division of Infectious Disease (Science), and Child Health Evaluative Sciences (Stephens), and Institute of Biomaterials and Biomedical Engineering and Division of Plastic and Reconstructive Surgery (Borschel), The Hospital for Sick Children, Toronto, Ont.

Contributors: Simeon Daeschler, Niclas Manson, Gregory Borschel, Jason Maynes and Michelle Science contributed to the conception and design of the work. Simeon Daeschler, Niclas Manson, Paul Chen, Kiana Tajdaran, Kaveh Mirmoeini, Jennifer Zhang, Katelyn Chan, Ali Darbandi, Libo Zhang, Leo Poon and Alex Chin contributed to the data acquisition. Simeon Daeschler and Derek Stephens performed the statistical analysis.
Simeon Daeschler, Niclas Manson and Gregory Borschel contributed to the interpretation of the data and drafted the manuscript. All of the authors revised it critically for important intellectual content, gave final approval of the version to be published and agreed to be accountable for all aspects of the work. Simeon Daeschler and Niclas Manson contributed equally to this article.

Funding: Funding was obtained from the Health and Medical Research Fund (COVID190116), Hong Kong and National Institute of Allergy and Infectious Diseases, National Institutes of Health (contract HHSN272201400006C). The funder had no role in the study design; in the collection, analysis, and interpretation of data; in the writing of the report; and in the decision to submit the article for publication.

Data sharing: All analyzed data sets are available from the corresponding author (gregory.borschel@sickkids.ca) upon reasonable request.

Acknowledgements: The authors acknowledge Dianna McCluskey, Ilda Ponte, Lucia Couto and Louis Konstant for their technical assistance with the $\mathrm{N} 95$ respirator reprocessing.

Accepted: July 15, 2020

Correspondence to: Gregory Borschel, gregory.borschel@sickkids.ca 